\title{
An Investigation of Local and National NWS Warning Outbreaks for Severe Convective Events
}

\author{
ZACHARY S. BRUICK \\ Department of Geography and Meteorology, Valparaiso University, Valparaiso, Indiana \\ CHRISTOPHER D. KARSTENS \\ Cooperative Institute for Mesoscale Meteorological Studies, University of Oklahoma, Norman, Oklahoma \\ NOAA/OAR/National Severe Storms Laboratory, Norman, Oklahoma
}

(Manuscript received 5 October 2016; review completed 21 December 2016)

\begin{abstract}
The National Weather Service (NWS) is charged with the responsibility of issuing severe weather warnings for the public whenever life and property may be in danger. During severe convective events, the NWS issues severe thunderstorm, tornado, and flash flood warnings. This study solely examines severe thunderstorm and tornado warnings conveying threats for wind, hail, and tornadoes.

Since 1 October 2007, the NWS has issued storm-based warnings, which cover smaller areas than the previous county-based system. Situational awareness and appropriate staffing levels are necessary to make warning operations successful within a NWS Weather Forecast Office (WFO). If storm coverage and severity are great enough, warning outbreaks can occur in which an NWS WFO has an anomalously high number of warnings valid at the same time-covering large portions of their areas of responsibility. In the top cases, there have been $\geq 10$ warnings in effect at the same time within a county warning area, and $\geq 30$ across the country.

A dichotomy exists between the environments that are associated with local and national tornado warning and severe thunderstorm warning outbreaks. Tornado warning outbreaks occur with high-end supercellular storm modes in high convective available potential energy (CAPE) and shear profiles. These events are often identified by the Storm Prediction Center as moderate or high risk with particularly dangerous situation tornado watches issued. Meanwhile, severe thunderstorm warning outbreaks transpire in mostly slight or enhanced risk areas with modest CAPE and low shear, which produce mainly pulse and linear thunderstorms. Verification statistics of these warnings indicate poorer performance compared to national averages-whether on local or national scales-with lower critical success index scores and higher false alarm ratios, although most events are warned during these outbreaks.
\end{abstract}

\section{Introduction}

A primary role for the National Weather Service (NWS) is the issuing of severe weather warnings to protect life and property. Issuing accurate and timely warnings for tornadoes and severe thunderstorms is crucial to the success of the NWS mission, as these hazards cause loss of life and significant damage each year. On 1 October 2007, the NWS adopted a stormbased warning strategy, a change to the former countybased system (Harrison and Karstens 2017). This updated warning strategy allows for less area to be warned for a storm, and thus, total warning area has been reduced by $84 \%$ from the old system (refer to https://verification.nws.noaa.gov/services/public/ contact.aspx). However, this does not mean that the total number of warnings has decreased. Rather more warnings are being issued by forecast offices to cover the same number of storms (Harrison and Karstens 2017). Because of this change in warning strategy, however, more work is required in creating and updating these warnings, causing a possible workload issue when numerous warnings in effect within a weather forecast office's (WFO) area of responsibility-referred to as a county warning area (CWA) - in situations with significant severe storm coverage.

The situational awareness of the office before storm development determines how prepared a staff is 
to handle the anticipated warning situation [Andra et al. 2002; Warning Division Training Division (WDTD) 2016]. Yet, warning operations and performance are highly dependent upon the individuals working a particular event (Boustead and Mayes 2014). When severe weather is anticipated within a WFO's CWA, the office's severe weather operations plan will call for a warning meteorologist to staff the radar desk, from which the meteorologist analyzes radar data and issues warnings for hazards to life and property (WDTD 2016). Additional personnel answer phone calls, disseminate warning information (e.g., via chat software), and analyze observations and model output in support of the warning meteorologist (Smith 2014). Some circumstances require multiple warning meteorologists working a CWA simultaneously by sectorizing operations (Andra et al. 2002). This division of labor is done to maximize the accuracy of warnings while preventing workload issues for the warning meteorologist(s), particularly for long duration events and/or events with multiple hazards. However, what happens in extreme situations in which multiple simultaneous warnings are in effect at the same time within a CWA? What are the meteorological factors leading to and characterizing these situations? How do these situations verify compared to annual averages? An investigation into these questions could offer knowledge that immediately benefits operational forecasters and could provide informative guidance to longer-term efforts aiming to modernize the current warning system used by the NWS (Rothfusz et al. 2014; Karstens et al. 2015). It is important to note that warning verification is a difficult task and far from perfect, especially during significant weather events. Because it is the responsibility of local offices to collect and receive storm reports that also verify their warnings, workload issues and a natural tendency of spotters to focus on the most severe event (e.g., less focus on seeking/reporting hail during tornado events) can result in some instances of severe weather being underreported.

The purpose of this paper is to investigate the extremes of distributions of simultaneous severe weather warnings, referred to as warning outbreaks in this paper. There is no formal definition of a warning outbreak in the literature, and as is discussed later, refining this definition could be a point of future research. This study particularly focuses on the mesoscale environments, severity of the events, and warning verification associated with these warning outbreaks. Section 2 explains the methods for this study, while section 3 discusses the results for the different types of warning outbreaks from WFO and national perspectives. Section 4 provides a discussion of the differences found between the different types of warning outbreaks and the warning outbreaks' impacts on warning verification. Section 5 closes the paper with a brief conclusion.

\section{Methods}

This study examines storm-based tornado and severe thunderstorm warnings issued by the NWS between 1 October 2007 and 2 June 2016. Archived warnings were obtained from the Iowa Environmental Mesonet (mesonet.agron.iastate.edu/) and information was extracted into shapefile format for analysis. Warnings were compared by type and issuing office in order to find times when multiple warnings of the same type were in effect at the same WFO and across the nation (i.e., warning outbreaks). These warning outbreak time periods were used to identify the top 10 instances for both warning types at the local office and national levels; these 40 warning instances were the only time periods examined in this study. All warnings issued within a convective day (1200 UTC-1200 UTC) that contained a top 10 warning instance were included in the warning outbreak event (Fig. 1). Verification statistics were calculated for the warning outbreak event. The number of warnings identified during these critical periods was compared with multiple additional warning databases to verify completeness of the dataset. It is important to note that the term "warning outbreak" has not been formally defined in literature as stated in the introduction; however, it will be used throughout this paper to indicate extreme occurrences of multiple valid warnings within a CWA during a single minute.

Level II radar data from the National Centers for Environmental Information radar archive (www.ncdc.noaa.gov/nexradinv) were analyzed to determine the storm mode and morphology for each case, using the methods developed by Smith et al. (2012). The possible modes defined by Smith et al. include supercell, marginal supercell, quasilinear convective system (QLCS), linear hybrid (embedded supercells within a linear complex), and disorganized. There also were subclasses to each group, allowing for classification into isolated cells, clusters, or different types of linear structures. The NWS Storm Prediction Center's (SPC) event archive (www.spc.noaa.gov/exper/archive/events) contains 


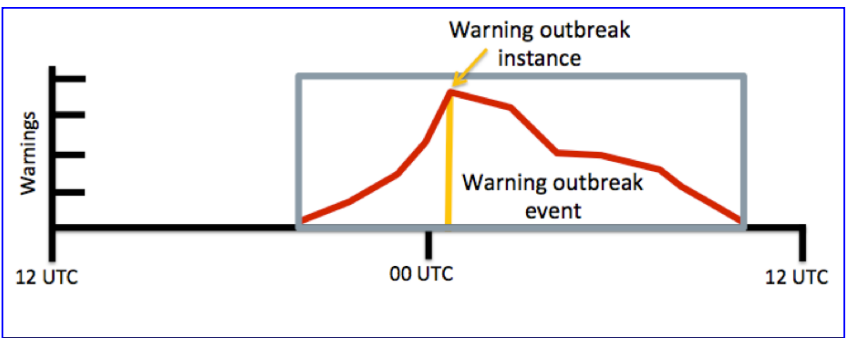

Figure 1. An example graphic demonstrating the occurrence of a warning outbreak instance (peak of warnings) and the warning outbreak event (all warnings) during a convective day. Click image for an external version; this applies to all figures hereafter.

storm reports, convective outlooks, and watches that were consulted for this study. Through SPC's mesoscale analysis (www.spc.noaa.gov/exper/ma archive) which is based on hourly surface observations and the Rapid Refresh model-surface-based convective available potential energy (SBCAPE), 0-6-km bulk shear, significant tornado parameter (STP), and supercell composite parameters (SCP) were recorded at the peak warning time for each event. The estimated maximum value of each parameter was recorded for each region of interest. STP is used as a composite index to discriminate between environments that produce tornadoes $(\mathrm{STP} \geq 1)$ and those that do not (Thompson et al. 2004). The modified equation accounts for instability, inhibition, storm-relative helicity, the lifted condensation level, and effective shear. SCP discriminates supercells from general thunderstorms, using most unstable (MUCAPE), bulk shear, and storm-relative helicity as the variables (Thompson et al. 2004).

Verification data for each warning issued during the warning outbreak events were obtained from the NWS Performance Branch (verification.nws.noaa.gov). The performance metrics of relevance for this study include probability of detection (POD), false alarm ratio (FAR), and the critical success index (CSI). FAR is defined as (1), where A represents hits and $B$ represents false detections (Wilks 2006; Table 1). POD, as defined by the NWS Performance Branch, is the mean of the percent event warned (PEW) values for the tornadoes within an event. Tornadoes are split into 1-min segments and PEW is calculated per NWS (2015) as (2). Using the FAR and POD values calculated above, CSI is then found using the equation (3).

Similarities and differences between severe thunderstorm warning and tornado warning outbreaks were analyzed to gain a better understanding about when and why these warning outbreaks occur. The issuance of warnings and effective communication of hazards to the public are necessary requirements during any severe weather event, as this is a primary mission of the NWS.

\section{Results}

\section{a. WFO tornado warning outbreaks}

Since storm-based warnings began on 1 October 2007, there have been 191,738 min, or $3195.63 \mathrm{~h}$, with $\geq 2$ tornado warnings valid for any one CWA (Fig. 2). As can be inferred from Fig. 2, approximately 64\% $(122,510)$ of these time periods had only two valid tornado warnings within the CWA. Ten concurrent tornado warnings within a CWA have only occurred for a total of 197 min since storm-based warnings began. The top 10 warning outbreak instances all fall above the 99.92nd percentile, indicating how rarely they occur.

The top 10 instances for tornado warnings are listed in Table 2 and shown in Figs. 3 and 4. The maximum amount of tornado warnings valid in any one time period was 14 , issued by WFO St. Louis, during a combined embedded supercell and QLCS event on 25 May 2011 (Figs. 3a and 4a). Eight of the 10 events occurred in a moderate or high risk area issued by the NWS SPC in any day one convective outlook prior to the event (Table 2). The other two events were defined as an

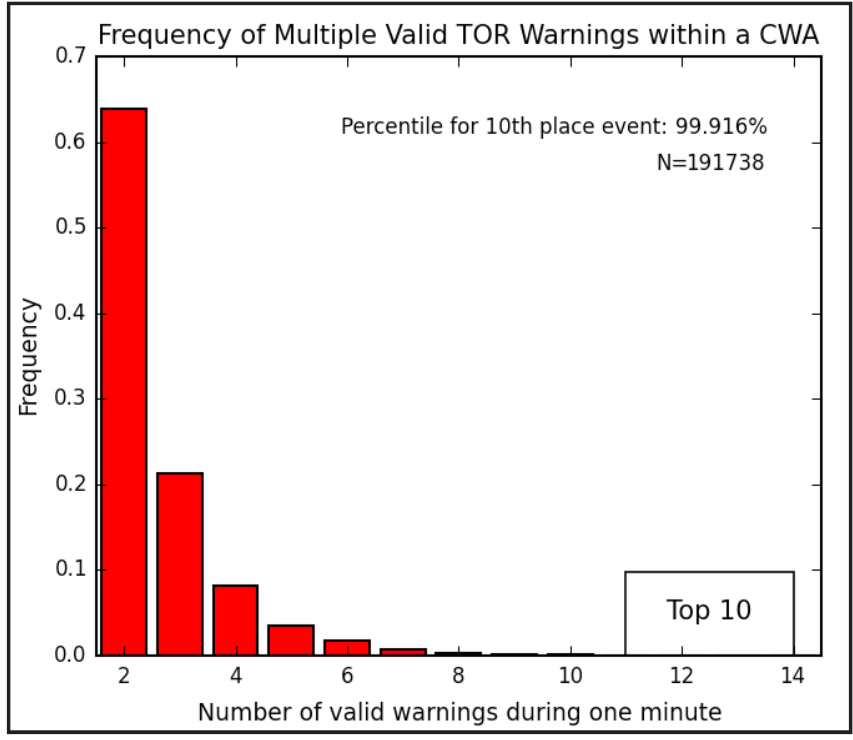

Figure 2. Frequency of 1 -min periods with $\geq 2$ tornado warnings valid for a single WFO CWA. 


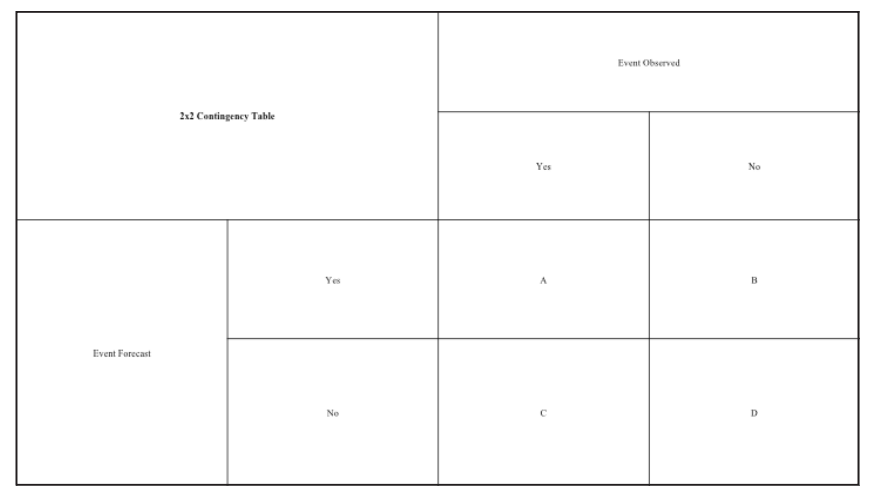

Table 1. The $2 \times 2$ contingency table used for the FAR calculations.

enhanced risk and a slight risk. Furthermore, six of the 10 affected CWAs were under a particularly dangerous situation (PDS) tornado watch during their respective events. PDS tornado watches are rarely issued, as they account for $8 \%$ of all tornado watches issued each year (Christenberry et al. 2010). A PDS tornado watch is issued when there is high confidence that significant (EF2+) tornadoes are likely to occur within the watch area. Almost all PDS tornado watches verify per SPC guidelines with only a 4\% FAR (Christenberry et al. 2010), giving meteorologists more awareness of the potential for tornadoes within severe thunderstorms during these events.

Out of the top 10 tornado warning outbreaks, six of them consisted of discrete or clustered supercells, while the other four events were QLCSs or smaller linear modes - per the analyses of the single-site radar data. Many of these events occurred in environments favorable for supercellular thunderstorms because there was moderate to high amounts of instability in the form of surface-based convective available potential energy (SBCAPE, maximum of 1000-4000 J kg-1) along with 15-36 m s-1 (30-70 kt) of maximum 0-6-km bulk shear to promote rotating updrafts (Table 2). The mean maximum STP value for the WFO tornado outbreaks was 4.14 , with a range of $0.5-9$ (Table 2).

Surprisingly, the top three events each had STP values of 2 , which indicates only a modest tornado environment (Thompson et al. 2012), while higher values of STP are associated with the bottom six results, including an STP value of 9 over the Huntsville CWA during the 27 April 2011 Super Outbreak (Table 2). During that event, WFO Huntsville issued 70 tornado warnings, which covered $349.62 \%$ of its CWA, meaning that on average any point within the CWA was under at least three tornado warnings during this event. Overall, these tornado warning outbreaks occurred in robust environments with the potential for actual tornado outbreaks (Grams et al. 2012).

The verification statistics of the warnings issued in these top 10 tornado warning outbreaks are mixed. For the warnings issued throughout the entirety of each event the FAR was 0.804 , the POD was 0.903 , and the CSI was 0.192 (Table 2). The fiscal year (FY) 2015 national averages are FAR $=0.695$, $\mathrm{POD}=0.579$, and CSI $=0.250$. Therefore, FAR increased 0.109 above the national average while POD increased by 0.324 . During tornado warning outbreaks there appears to be a tendency for more warnings to be issued so that events are not missed (i.e., higher POD), but this also causes the FAR to increase. The difference in CSI indicates this trend, as it decreased by 0.058 from the national average during the warning outbreaks - despite the increase in POD.

\section{b. National tornado warning outbreaks}

Nationwide tornado warning outbreaks are slightly more common, with 199,434 min of multiple valid tornado warnings since storm-based warnings began (Fig. 5), with the top 10 cases falling above the 99.39th percentile. These cases range from 20 to 45 active tornado warnings at the outbreak instance (Table 3) with entire event tornado warning counts of 64-432. Six cases were deemed high risk, three were moderate, and one was a slight risk, as issued by the SPC. Additionally, eight of the events had at least one PDS tornado watch issued, with 20 PDS tornado watches issued in total during the 10 events (Table 3). Similar to the WFO tornado warning outbreaks, these days with extreme numbers of tornado warnings occurred when tornado outbreaks were expected across a broad area.

The environments that these warning outbreaks occurred in was more potent than the individual office warning outbreaks, as mean SBCAPE was $1975 \mathrm{~J} \mathrm{kg-1}$ (with a range of 250-4000 J kg-1), while maximum bulk shear ranged from 25 to $46 \mathrm{~m} \mathrm{~s}-1$ (50 to $90 \mathrm{kt}$ ) with a mean of $33.4 \mathrm{~m} \mathrm{~s}-1(65 \mathrm{kt})$. The mean STP was 4.70 with a range of $1-11$ (Table 3). The 27 April 2011 Super Outbreak - during which 292 tornadoes occurred-featured an incredible parameter space with $3000 \mathrm{~J} \mathrm{~kg}-1$ of SBCAPE, $41.2 \mathrm{~m} \mathrm{~s}-1$ (80 kt) of bulk shear, and an STP value of 11 when there were 45 active tornado warnings at the outbreak instance across the southeastern United States. A total of 432 


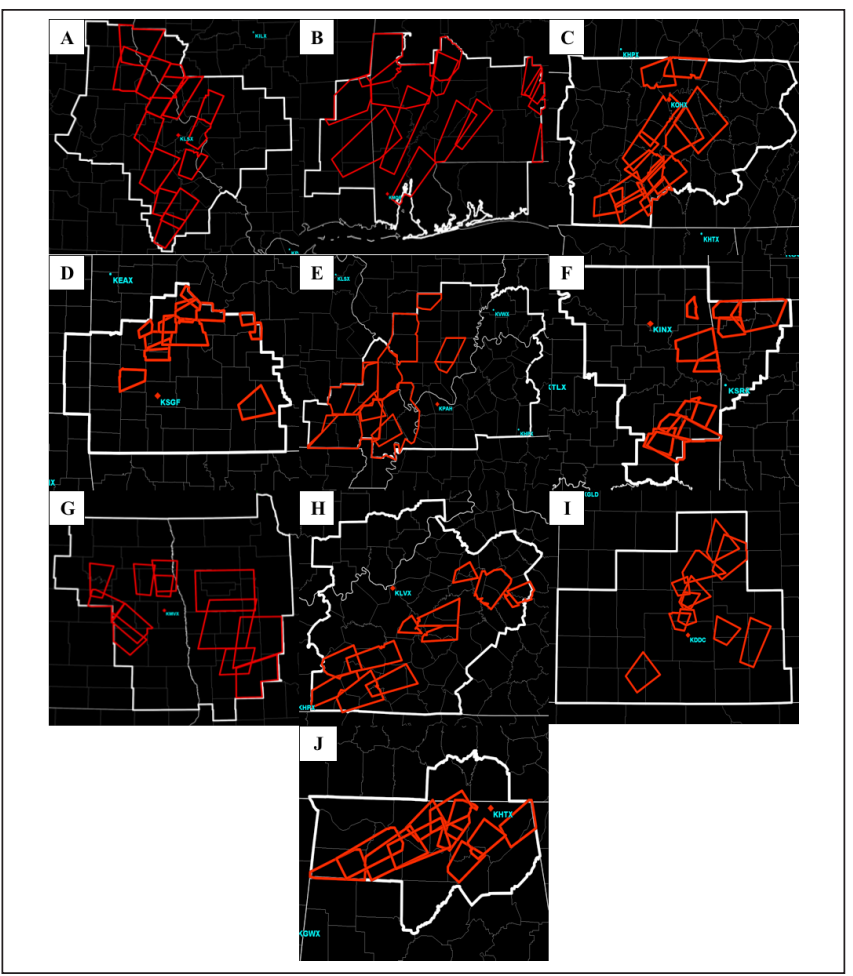

Figure 3. The active warnings at the peak of the top 10 local tornado warning outbreaks, ordered one through 10 ( A to J, respectively).

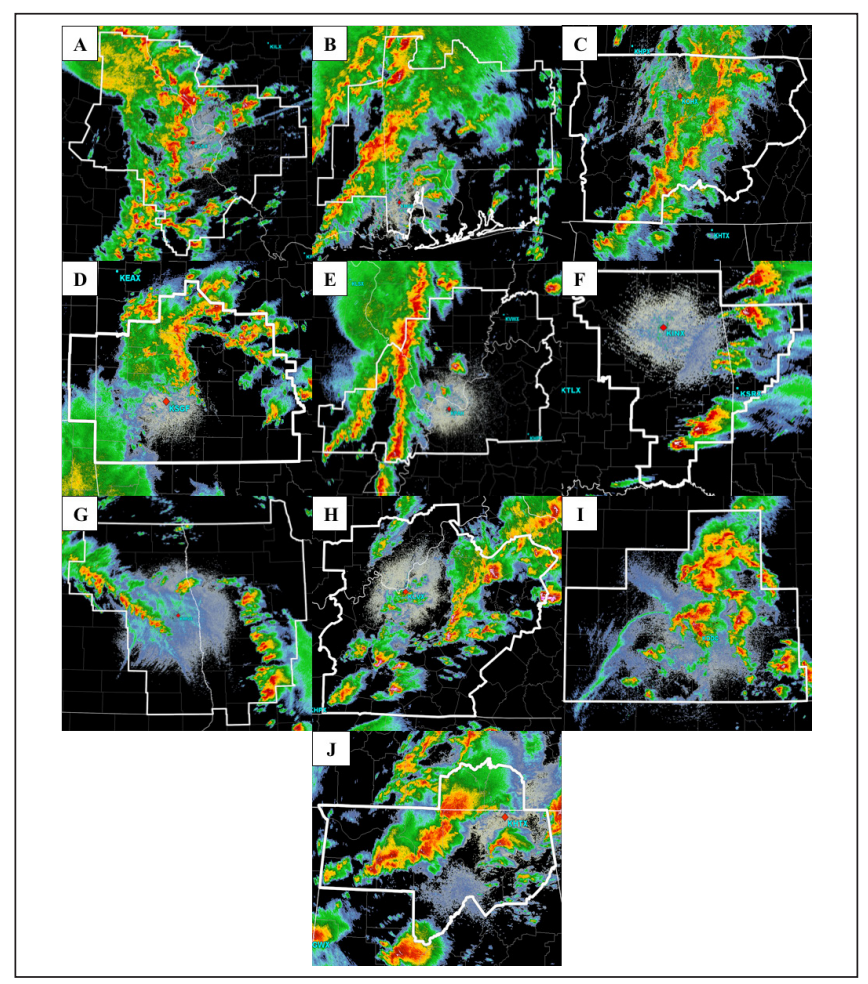

Figure 4. The $0.5^{\circ}$ base reflectivity at the peak of the top 10 local tornado warning outbreaks, ordered the same as Fig. 3. tornado warnings were issued that day across a broad portion of the southeastern United States, with many tornado warnings also issued on the previous day; this was the \#3 national tornado warning outbreak, with 36 warnings at the outbreak instance and 314 warnings during the entire event (Table 3). On the opposite end of the spectrum, the slight risk event on 10 June 2009 only had a STP value of 1 at the peak warning time period.

The verification of the warnings faired similarly to the WFO warning outbreak statistics, with a FAR of 0.819 , a POD of 0.861 , and a CSI of 0.176 (Table 3). When compared to the FY15 national averages, the FAR increased by 0.124 and POD increased by 0.282 , while CSI fell by 0.074 . During national tornado warning outbreaks the warnings tend to cover more events than normal at the expense of a higher FAR (similar to the local warning outbreaks). This seems to indicate that forecasters at different offices respond to these types of events in a similar manner-over-warning storms so that events are not missed, especially during higher-end tornado outbreaks.

\section{c. WFO severe thunderstorm warning outbreaks}

Severe thunderstorm warning outbreaks are similarly as infrequent as tornado warning outbreaks, as there have been $1,804,121$ min with $\geq 2$ active severe thunderstorm warnings, causing the top 10 warning outbreak periods to be above the 99.99th percentile (Fig. 6). This increased percentile score, when compared to local tornado warning outbreaks, is due to the increased amount of time with multiple

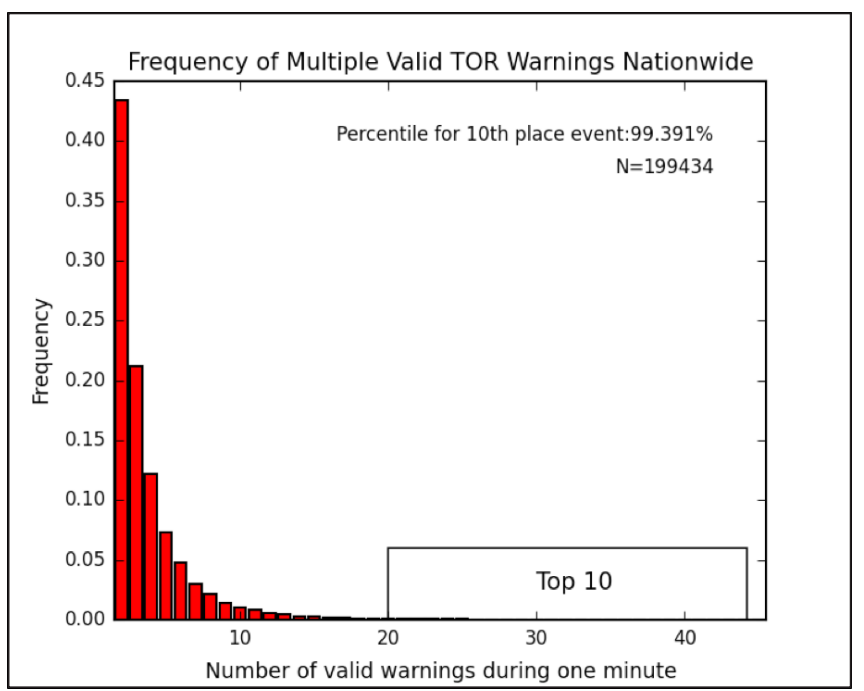

Figure 5. Same as Fig. 2 except for the nation. 


\begin{tabular}{|c|c|c|c|c|c|c|c|c|c|c|c|c|}
\hline WFO & Date & $\begin{array}{c}\text { Time } \\
\text { (UTC } \\
\text { ) }\end{array}$ & $\begin{array}{c}\text { Peak \# of } \\
\text { Warnings }\end{array}$ & $\begin{array}{r}\text { Total \# of } \\
\text { Warnings }\end{array}$ & $\begin{array}{c}\text { Convective } \\
\text { Outlook }\end{array}$ & $\begin{array}{c}\text { PDS } \\
\text { Watch }\end{array}$ & $\begin{array}{c}\text { SBCAPE } \\
\left(\mathrm{J} \mathrm{kg}^{-1}\right)\end{array}$ & $\begin{array}{c}\text { Bulk } \\
\text { Shear } \\
\text { (kts) }\end{array}$ & STP & FAR & POD & CSI \\
\hline St. Louis & $05 / 25 / 11$ & $20: 45$ & 14 & 45 & High* & Yes & 3000 & 40 & 2 & 0.933 & 0.917 & 0.066 \\
\hline Mobile & $12 / 25 / 12$ & $23: 15$ & 14 & 36 & Moderate & Yes & 1000 & 60 & 2 & 0.806 & 0.970 & 0.193 \\
\hline Nashville & $04 / 10 / 09$ & $18: 15$ & 13 & 37 & Moderate & Yes & 1000 & 60 & 2 & 0.730 & 0.680 & 0.240 \\
\hline Springfield & $06 / 11 / 09$ & $00: 15$ & 13 & 18 & Slight & No & 4000 & 30 & 0.5 & 0.944 & 0.125 & 0.040 \\
\hline Paducah & $05 / 25 / 11$ & $23: 15$ & 12 & 46 & High & Yes & 3000 & 50 & 6 & 0.761 & 0.966 & 0.237 \\
\hline Tulsa & $05 / 10 / 08$ & $23: 30$ & 12 & 23 & Moderate & No & 2000 & 60 & 6 & 0.652 & 0.889 & 0.333 \\
\hline $\begin{array}{l}\text { Grand } \\
\text { Forks }\end{array}$ & $06 / 17 / 10$ & $21: 30$ & 12 & 33 & Moderate & No & 2000 & 60 & 5 & 0.788 & 0.958 & 0.210 \\
\hline Louisville & $03 / 02 / 12$ & $22: 15$ & 12 & 41 & High & Yes & 1000 & 70 & 5 & 0.902 & 1.000 & 0.098 \\
\hline $\begin{array}{l}\text { Dodge } \\
\text { City }\end{array}$ & $05 / 25 / 16$ & $00: 25$ & 11 & 34 & Enhanced & No & 3000 & 40 & 3 & 0.824 & 0.843 & 0.171 \\
\hline Huntsville & $04 / 27 / 11$ & $21: 45$ & 11 & 70 & High & Yes & 1000 & 70 & 9 & 0.743 & 0.907 & 0.251 \\
\hline & & & & & & Avg: & 2100 & 54 & 4.14 & 0.804 & 0.903 & 0.192 \\
\hline & & & & & & & & \multicolumn{2}{|l|}{ Nat } & 0.695 & 0.579 & 0.250 \\
\hline
\end{tabular}

Table 2. The top 10 tornado warning outbreak events since 1 October 2007. The asterisk (*) indicates an upgrade in the convective outlook from moderate to high risk at 1630 UTC.

\begin{tabular}{|c|c|c|c|c|c|c|c|c|c|c|c|c|}
\hline Area & Date & $\begin{array}{c}\text { Time } \\
\text { (UTC } \\
\text { ) }\end{array}$ & $\begin{array}{l}\text { Peak \# of } \\
\text { Warnings }\end{array}$ & $\begin{array}{l}\text { Total\# of } \\
\text { Warnings }\end{array}$ & $\begin{array}{l}\text { Convective } \\
\text { Outlook }\end{array}$ & $\begin{array}{c}\text { PDS } \\
\text { Watch }\end{array}$ & $\begin{array}{l}\text { SBCAPE } \\
\left(\mathrm{J} \mathrm{kg}^{-1}\right)\end{array}$ & $\begin{array}{c}\text { Bulk } \\
\text { Shear } \\
\text { (kts) }\end{array}$ & STP & FAR & POD & CSI \\
\hline Southeast & $04 / 27 / 11$ & $22: 45$ & 45 & 432 & High & 5 & 3000 & 80 & 11 & 0.773 & 0.884 & 0.220 \\
\hline OH River & $03 / 02 / 12$ & $23: 15$ & 37 & 283 & High & 3 & 1000 & 80 & 5 & 0.841 & 0.911 & 0.157 \\
\hline Southeast & $04 / 27 / 11$ & $00: 15$ & 36 & 314 & High & 3 & 2000 & 60 & 5 & 0.828 & 0.823 & 0.166 \\
\hline $\begin{array}{l}\text { Central MS } \\
\text { River }\end{array}$ & $05 / 25 / 11$ & $22: 15$ & 32 & 278 & High & 3 & 3000 & 50 & 6 & 0.856 & 0.831 & 0.140 \\
\hline $\mathrm{IN} / \mathrm{OH} / \mathrm{KY}$ & $10 / 26 / 10$ & $16: 00$ & 29 & 233 & High* & 1 & 250 & 90 & 2 & 0.880 & 0.717 & 0.115 \\
\hline $\mathrm{MS} / \mathrm{AL}$ & $04 / 15 / 11$ & $22: 30$ & 26 & 192 & Moderate & 0 & 2000 & 60 & 7 & 0.771 & 0.962 & 0.227 \\
\hline $\mathrm{MS} / \mathrm{AL} / \mathrm{TN}$ & $01 / 10 / 08$ & $20: 45$ & 22 & 95 & Moderate** & 1 & 500 & 60 & 2 & 0.863 & 0.925 & 0.270 \\
\hline $\begin{array}{c}\mathrm{KY} / \mathrm{TN} / \mathrm{AL} / \mathrm{G} \\
\mathrm{A}\end{array}$ & $04 / 10 / 09$ & $18: 00$ & 21 & 183 & High*** & 2 & 2000 & 60 & 4 & 0.820 & 0.844 & 0.175 \\
\hline $\mathrm{TX} / \mathrm{OK} / \mathrm{MO}$ & $06 / 11 / 09$ & $00: 15$ & 21 & 64 & Slight & 0 & 4000 & 50 & 1 & 0.859 & 0.607 & 0.129 \\
\hline $\mathrm{OK} / \mathrm{MO} / \mathrm{SE}$ & $05 / 11 / 08$ & $00: 00$ & 20 & 123 & Moderate & 2 & 2000 & 60 & 4 & 0.724 & 0.925 & 0.270 \\
\hline & & & & & & Avg: & 1975 & 65 & 4.70 & 0.819 & 0.861 & 0.176 \\
\hline & & & & & & & & \multicolumn{2}{|c|}{ Nat. Avg: } & 0.695 & 0.579 & 0.250 \\
\hline
\end{tabular}

Table 3. The top 10 national tornado warning outbreaks with verification (from the NWS Performance Branch) and mesoscale analysis data (www.spc.noaa.gov/exper/ma archive/). The asterisk (*) signifies a high risk outlook was due to damaging wind; the double asterisks (**) indicate an upgrade from a slight risk at the 1630 UTC outlook; and the triple asterisks $(* * *)$ represent an upgrade from a moderate risk at 2000 UTC.

warnings. As can be inferred from Fig. $6,<60 \%$ of all time periods (i.e., 1,068,697 of 1,804,121) with multiple severe thunderstorm warnings had two warnings valid, $10 \%(178,239)$ of time periods had four warnings, and approximately $2 \%(33,657)$ of time periods had six valid warnings. The top 10 warning outbreak instances ranged from 13 to 16 valid warnings during the peak of the warning outbreak events (Figs. 7 and 8).

Other than their rare nature, the characteristics of severe thunderstorm warning outbreaks stand in contrast to tornado warning outbreaks. Seven of the 10 cases occurred in slight risk areas per convective outlooks issued by the SPC (Table 4). The other three cases were in moderate risk areas. Three events experienced upgrades in the convective outlook areas during the day leading up to peak warning time. Two cases went from "see text" areas, now defined as a marginal risk (NWS 2016), to slight risks, while one case was upgraded from a slight to moderate risk (Table 4). Only one event had a PDS severe thunderstorm watch issued-a 
derecho event in the Memphis CWA on 12 June 2009which was actually the 10th-place severe thunderstorm warning outbreak. One outbreak event went without any convective watch issued (Knoxville CWA, 2 July 2012).

Out of the top 10 warning outbreak instances, five were QLCS cases, while the rest were in disorganized linear or clustered modes per the Smith et al. (2012) classification method. Some of the disorganized linear cases may be colloquially referred to as QLCSs, but they did not meet the length or aspect ratio requirements established for the QLCS class by Smith et al. The environments associated with these events had a maximum SBCAPE of 250-3,000 J kg-1 with a mean of 1,675 J kg-1, maximum bulk shear of 5-36 $\mathrm{m} \mathrm{s}-1$ (10-70 kt) and mean of $17.5 \mathrm{~m} \mathrm{~s}-1$ (34 kt), and a maximum supercell composite of 0-20 and mean of 5.75 (Table 4). The SCP mean corresponds well with the median SCP values for QLCS events (4.0) and hybrid events (6.5), as found by Thompson et al. (2012). Four of the cases had SCP $\leq 2$, associated with very weak vertical wind shear throughout the lowest $6 \mathrm{~km}$ of the troposphere. With enough instability and lift, however, initiation and maturation of severe thunderstorms occurred and warning outbreaks ensued.

Like the warnings issued during tornado warning outbreaks, the warnings valid during a severe thunderstorm warning outbreak did not verify as well as the FY15 national average. The mean FAR was 0.651, the mean POD was 0.927, and the mean CSI was 0.339 (Table 4). The FY15 verification national means

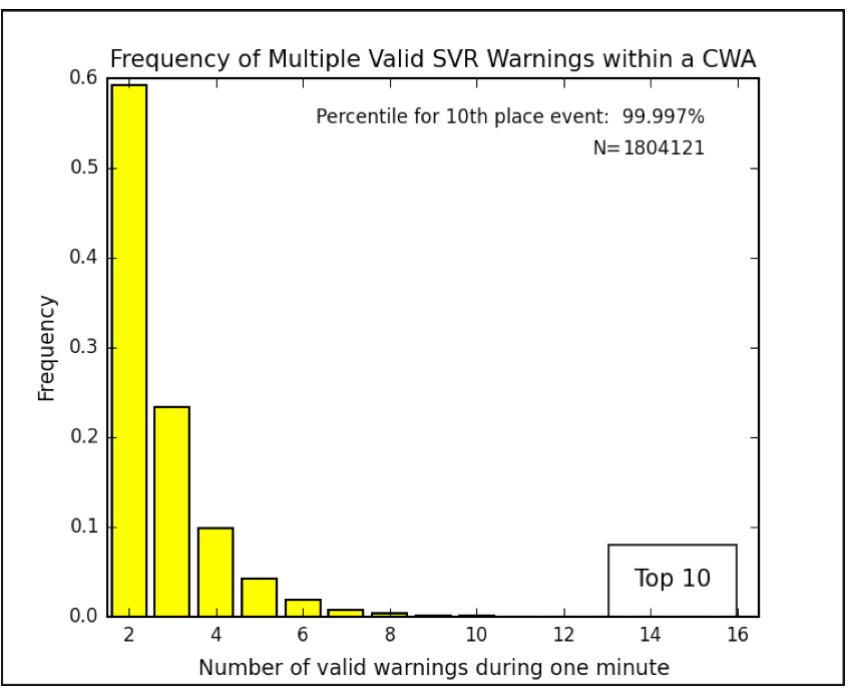

Figure 6. Same as Fig. 2 except for severe thunderstorm warnings.

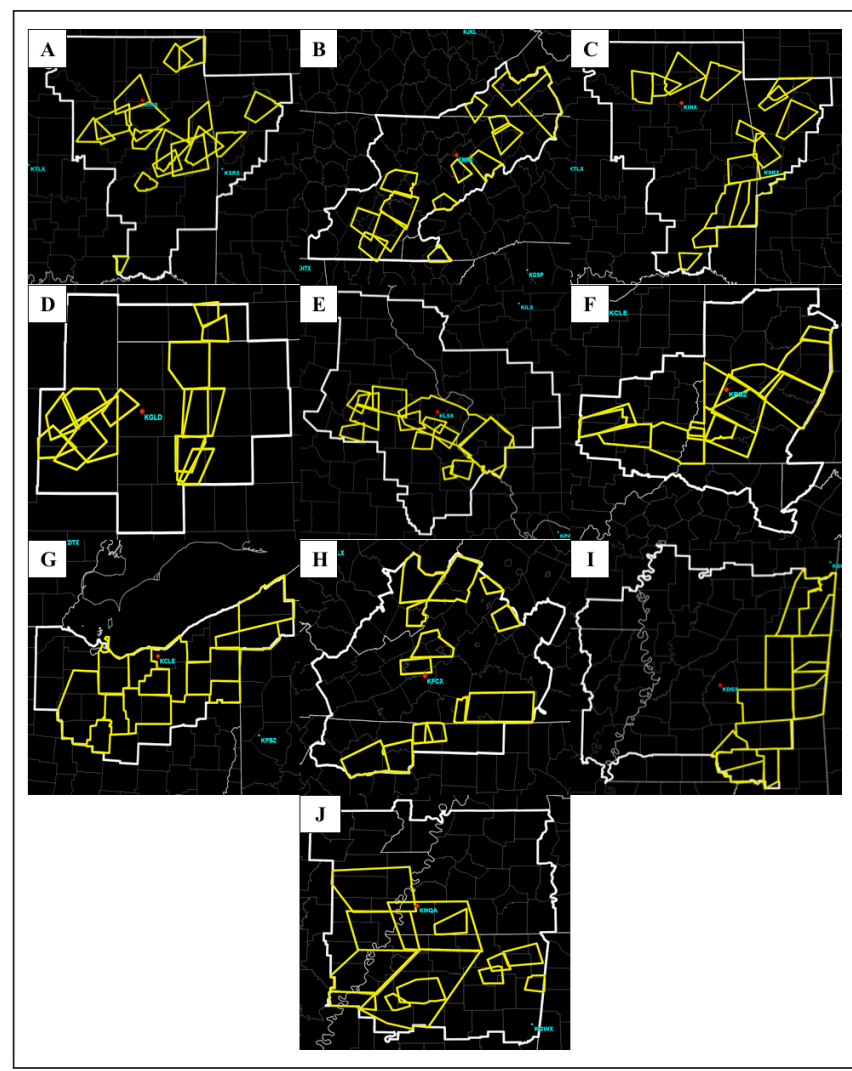

Figure 7. Same as Fig. 3 except for severe thunderstorm warning outbreaks.

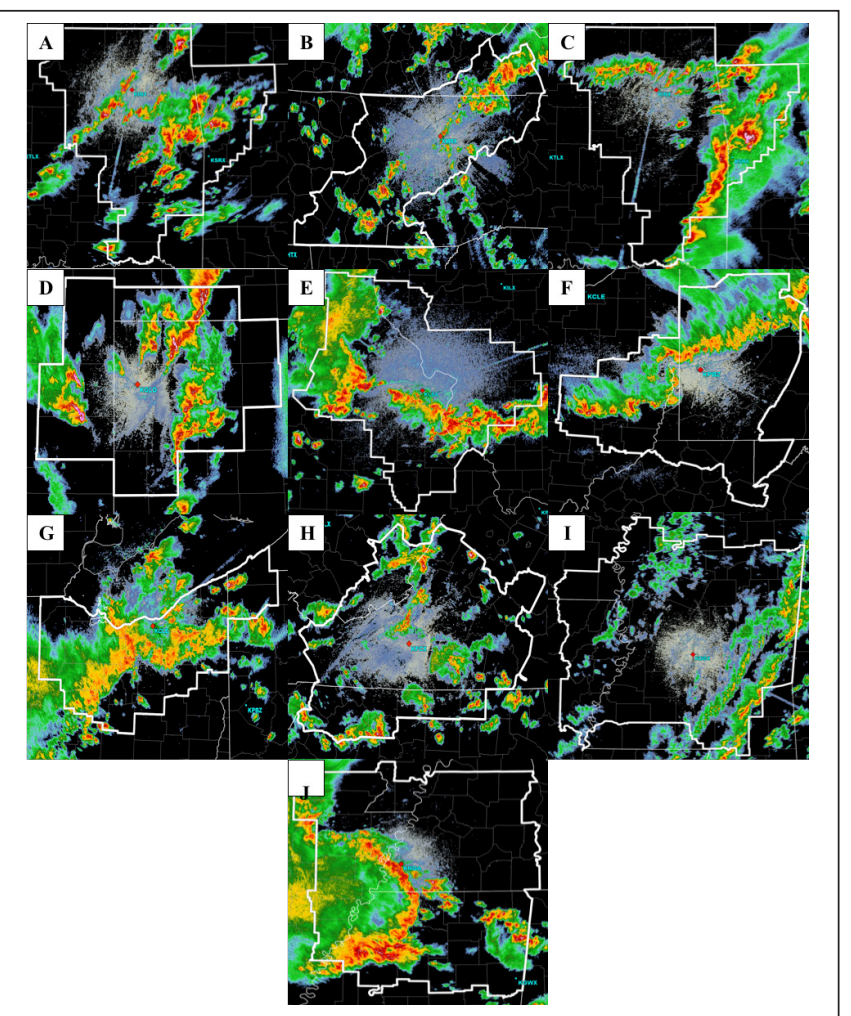

Figure 8. Same as Fig. 4 except for severe thunderstorm warning outbreaks. 
were 0.491 for FAR, 0.782 for POD, and 0.446 for CSI. During these outbreaks, the FAR rose by 0.160 , the POD increased by 0.145 , and the CSI dropped by 0.107 compared to the national averages. Similar to the tornado warning outbreaks, many warnings were issued to cover every event possible at the expense of an increased FAR, as the drop in CSI indicates.

\section{d. National severe thunderstorm warning outbreaks}

Since storm-based warnings began, multiple severe thunderstorm warnings have occurred at the same time across the country for $1,070,016 \mathrm{~min}$, or 743.07 of $3,168(23.5 \%)$ possible days. There is less time with multiple severe thunderstorm warnings from a national perspective than a local one, as many overlapping cases from different CWAs are lumped into one event. When multiple warnings were in effect, 224,407 of the $1,070,016$ time periods (or 21\%) had two valid warnings, while $15 \%$ of the time periods had $\geq 10$ valid warnings during a given minute. The top 10 national severe thunderstorm warning outbreaks had 57-82 active warnings during the warning outbreak instanceabout double of the national tornado warning outbreaks (20-45) — causing these events to be in the top 99.98th percentile (Fig. 9). During the entire event, total severe thunderstorm warnings ranged from 311 to 516. All events took place near the Mississippi River valley or east of it, with only a few events over the southern Great Plains and Ozarks.

Similar to the local severe thunderstorm warning outbreaks and in contrast to the national tornado warning outbreaks, the days that the national severe thunderstorm warning outbreaks occurred were often deemed lower-end events with modest supporting environments. Seven of the 10 events were slight risk days according to the SPC (Table 5), although six of those days would now be considered enhanced risks under the upgraded guidelines for convective outlooks (NWS 2016). Two events were considered moderate risks, while 26 April 2011 (one day in the 2011 Super Outbreak) was a high risk day. The only PDS watches during these 10 events were issued during 26 April 2011. All other events were covered with regular severe thunderstorm or tornado watches.

The mesoscale analysis statistics reflect a somewhat different story though, as the mean maximums of SBCAPE, bulk shear, and the SCP were 2,500 J kg-1, $18.5 \mathrm{~m} \mathrm{~s}-1$ (36 kt), and 8.85, respectively (Table 5). The mean maximum SBCAPE is the highest of any

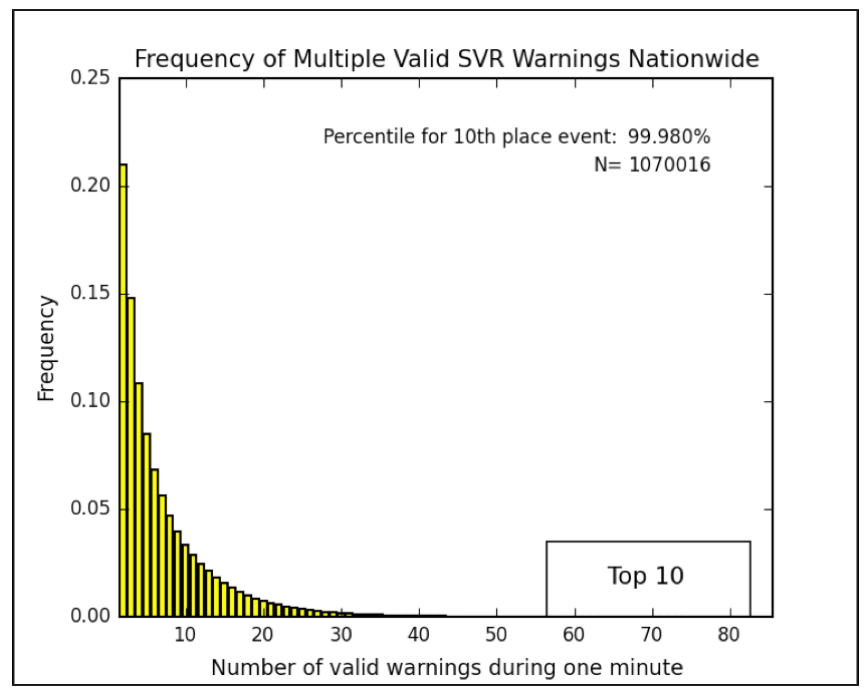

Figure 9. Same as Fig. 2 except for severe thunderstorm warnings for the nation.

category, and the SCP increased by 3.10 relative to that for the local severe thunderstorm warning outbreaks. The vertical wind shear, which ranged from 10 to $31 \mathrm{~m}$ $\mathrm{s}-1$ (20 to $60 \mathrm{kt})$, is the limiting factor for making these events severe thunderstorm outbreaks and not tornado outbreaks. According to Thompson et al. (2012), mean bulk wind shear was $15.4(30 \mathrm{kt})$ for marginal rightmoving supercells, $22.6 \mathrm{~m} \mathrm{~s}-1$ (44 kt) for QLCSs, and $25.2 \mathrm{~m} \mathrm{~s}-1$ (49 kt) for discrete right-moving supercells. Although there are multiple storm modes involved in each event, the wind shear present in most cases was supportive of marginal supercells and QLCS-type events, preventing tornadoes from being a bigger threat despite greater instability and higher mean SCP present in these cases.

The verification of these warnings remains similar to all previous categories. The FAR, POD, and CSI were $0.678,0.836$, and 0.303 (Table 5), respectively. Compared to the FY1 5 national averages, FAR increased 0.187, POD increased 0.054, and CSI decreased 0.143. Once again, poor performance of warnings is indicated by the large decrease in CSI, although a greater percentage of events were warned. These results further support the notion that the over-warning of storms is not only a local office phenomenon, but is widespread across the country during these rare situations in which multiple warnings are in effect simultaneously.

\section{Discussion}

Warning severe thunderstorms and tornadoes is a 


\begin{tabular}{|c|c|c|c|c|c|c|c|c|c|c|c|c|}
\hline WFO & Date & $\begin{array}{c}\text { Time } \\
\text { (UTC } \\
\text { ) }\end{array}$ & $\begin{array}{l}\text { Peak \# of } \\
\text { Warnings }\end{array}$ & $\begin{array}{l}\text { Total\# of } \\
\text { Warnings }\end{array}$ & $\begin{array}{c}\text { Convective } \\
\text { Outlook }\end{array}$ & Watch & $\begin{array}{c}\text { SBCAPE } \\
\left(\mathrm{J} \mathrm{kg}^{-1}\right)\end{array}$ & $\begin{array}{c}\text { Bulk } \\
\text { Shear } \\
\text { (kts) }\end{array}$ & SCP & FAR & POD & CSI \\
\hline Tulsa & $05 / 12 / 11$ & $23: 15$ & 16 & 37 & Slight* & Yes & 2000 & 40 & 6 & 0.676 & 0.885 & 0.311 \\
\hline Knoxville & $07 / 02 / 12$ & $03: 30$ & 14 & 26 & Slight** & No & 1000 & 30 & 0 & 0.462 & 1.000 & 0.538 \\
\hline Tulsa & $04 / 26 / 11$ & $23: 15$ & 14 & 26 & Moderate & Yes & 1000 & 60 & 20 & 0.654 & 0.844 & 0.325 \\
\hline Goodland & $05 / 29 / 13$ & $21: 30$ & 14 & 38 & Moderate & Yes & 2000 & 60 & 8 & 0.684 & 0.905 & 0.306 \\
\hline St. Louis & $07 / 03 / 11$ & $20: 00$ & 14 & 24 & Slight** & Yes & 3000 & 30 & 1 & 0.583 & 0.764 & 0.369 \\
\hline Pittsburgh & $06 / 25 / 13$ & $23: 00$ & 13 & 45 & Slight* & Yes & 2000 & 20 & 4 & 0.778 & 0.953 & 0.220 \\
\hline Cleveland & $07 / 10 / 13$ & $19: 45$ & 13 & 28 & Slight* & Yes & 2000 & 20 & 4 & 0.750 & 0.914 & 0.244 \\
\hline Blacksburg & $06 / 03 / 09$ & $20: 15$ & 13 & 33 & Slight* & Yes & 2000 & 10 & 0.5 & 0.394 & 0.951 & 0.588 \\
\hline Jackson & $12 / 20 / 12$ & $13: 00$ & 13 & 31 & Slight & Yes & 250 & 70 & 2 & 0.613 & 0.930 & 0.376 \\
\hline Memphis & $06 / 12 / 09$ & $22: 00$ & 13 & 39 & $\begin{array}{c}\text { Moderate** } \\
*\end{array}$ & PDS & 1000 & 40 & 12 & 0.795 & 0.976 & 0.204 \\
\hline & & & & & & Avg: & 1625 & 38 & 5.75 & 0.651 & 0.927 & 0.339 \\
\hline & & & & & & & & \multicolumn{2}{|c|}{ Nat. Avg: } & 0.491 & 0.782 & 0.446 \\
\hline
\end{tabular}

Table 4. The top 10 severe thunderstorm warning outbreaks since 1 October 2007. An asterisk (*) indicates a slight risk that would be considered an enhanced risk under the newest SPC guidelines; the double asterisks (**) signify an upgrade from a marginal to slight risk at 1630 UTC or later; and the triple asterisks $(* * *)$ designate a series of upgrades from a slight risk to a moderate risk at 1630 UTC.

\begin{tabular}{|c|c|c|c|c|c|c|c|c|c|c|c|c|}
\hline Area & Date & $\begin{array}{c}\text { Time } \\
\text { (UTC } \\
\text { ) }\end{array}$ & $\begin{array}{l}\text { Peak \# of } \\
\text { Warnings }\end{array}$ & $\begin{array}{l}\text { Total \# of } \\
\text { Warnings }\end{array}$ & $\begin{array}{c}\text { Convective } \\
\text { Outlook }\end{array}$ & $\begin{array}{c}\text { PDS } \\
\text { Watch }\end{array}$ & $\begin{array}{c}\text { SBCAPE } \\
\left(\mathrm{J} \mathrm{kg}^{-1}\right)\end{array}$ & $\begin{array}{c}\text { Bulk } \\
\text { Shear } \\
\text { (kts) }\end{array}$ & SCP & FAR & POD & CSI \\
\hline $\mathrm{WI} / \mathrm{IL} / \mathrm{MO} / \mathrm{OK}$ & $05 / 22 / 11$ & $23: 00$ & 82 & 484 & Moderate & No & 3000 & 40 & 28 & 0.760 & 0.769 & 0.224 \\
\hline OH River & $06 / 02 / 09$ & $22: 00$ & 66 & 311 & Slight* & No & 1000 & 30 & 2 & 0.688 & 0.795 & 0.289 \\
\hline SE US/ID/MT & $07 / 22 / 08$ & $20: 15$ & 65 & 516 & Slight* & No & 2000 & 20 & 0.5 & 0.628 & 0.804 & 0.341 \\
\hline Apps/Carolinas & $07 / 01 / 12$ & $22: 00$ & 63 & 498 & Slight* & No & 3000 & 30 & 4 & 0.649 & 0.933 & 0.343 \\
\hline Apps/Mid So & $08 / 05 / 10$ & $21: 45$ & 61 & 344 & Slight* & No & 3000 & 30 & 6 & 0.645 & 0.852 & 0.334 \\
\hline NE/Apps & $06 / 09 / 11$ & $20: 45$ & 60 & 369 & Moderate** $^{* *}$ & No & 3000 & 50 & 8 & 0.687 & 0.914 & 0.304 \\
\hline Midwest/Apps & $06 / 22 / 11$ & $00: 00$ & 60 & 368 & Slight & No & 2000 & 30 & 4 & 0.641 & 0.783 & 0.326 \\
\hline NE/Apps & $05 / 26 / 11$ & $21: 30$ & 59 & 349 & Slight* & No & 2000 & 40 & 8 & 0.696 & 0.819 & 0.285 \\
\hline $\mathrm{TX} / \mathrm{LA} / \mathrm{MS} / \mathrm{AL}$ & $04 / 26 / 11$ & $23: 15$ & 58 & 445 & High?? & 3 & 3000 & 60 & 20 & 0.757 & 0.705 & 0.220 \\
\hline LA/SE US & $08 / 02 / 08$ & $21: 45$ & 57 & 391 & Slight* & No & 3000 & 30 & 8 & 0.621 & 0.894 & 0.362 \\
\hline & & & & & & Avg: & 2500 & 36 & 8.85 & 0.678 & 0.836 & 0.303 \\
\hline & & & & & & & & \multicolumn{2}{|l|}{ Nat } & 0.491 & 0.782 & 0.446 \\
\hline
\end{tabular}

Table 5. The top 10 national severe thunderstorm warning outbreaks with verification (from the NWS Performance Branch) and mesoscale analysis data (www.spc.noaa.gov/exper/ma archive/). An asterisk (*) signifies a slight risk that would now qualify as an enhanced risk; the double asterisks $(* *)$ indicate an upgrade to a moderate risk at 1630 UTC; and the triple asterisk indicates an upgrade to a high risk at 1300 UTC.

difficult process, as forecasters strive to warn as many events as possible without issuing false alarms. When numerous storms occur at the same time within a CWA, warning meteorologists must make faster decisions than normal in order to disseminate warnings in a timely fashion. While these demanding situations are limited in frequency, forecasters must be prepared to deal with them when they arise (Boustead and Mayes 2014). This study focused on top 10 events for WFO and national severe thunderstorm and tornado warnings outbreaks to develop a better understanding about when and why these situations occur.

Through recent service assessments by the NWS, an emphasis has been placed on understanding how to improve the FAR while maintaining the current POD, especially after the 2011 Joplin, Missouri, EF5 tornado and southeastern United States Super Outbreak (NWS 2005, 2011a,b). However, it is not clear if such 
an improvement in warning performance can occur because of the complex relationship between FAR and POD (Brooks 2004; NWS 2011b). In order to decrease the number of false alarms, fewer warnings must be issued. However, attempting such an effort increases the possibility that severe events will not be warned. This relationship is due to the fact that FAR is sensitive to the number of warnings issued, while POD is sensitive to the number of events that occur. However, this does not mean that they are independent of each other, as a high POD requires warnings to be issued for severe events. For example, with the FY15 FAR national average at 0.695 , there were 625 verified tornado warnings out of 2046 total tornado warnings, or three verified warnings for every 10 tornado warnings issued.

From 2008 to 2015, an average of 3363 tornado warnings and 22,780 severe thunderstorm warnings have been issued each year across the United States. During this same period, an average of 935 tornado events and 20,158 severe thunderstorm events occurred annually. The average outbreak tornado warning count for the top 10 national cases was 220 with an average tornado count of 100 , while the average outbreak severe thunderstorm warning count was 410 with an average severe thunderstorm event count of 602 . This implies that if a tornado warning outbreak occurs during a typical year, $6.5 \%$ of the warnings and $10.7 \%$ of the tornadoes for the year occur during the outbreak event. Meanwhile, $1.8 \%$ of the warnings and $3.0 \%$ of the events for the year occur during severe thunderstorm warning outbreaks. During extreme years, warning outbreaks can play a larger role in determining the yearly statistics. For example, 2011 contained four of the top 10 warning outbreaks. During these four events, 1,216 out of 4,634 total warnings $(26.2 \%)$ for the year were issued, with 632 out of 1,452 tornadoes (43.5\%) for the year occurring. Because a large percentage of tornado events occur during tornado warning outbreaks, the event's POD score translates to a substantial improvement in annual warning performance by the NWS most dramatically. However, the national FAR average cannot be improved as much during national warning outbreaks, as a small percentage of warnings occur during these outbreaks.

The ranking of each warning outbreak was done based on the number of warnings valid during the warning outbreak instance. If the ranking was rather done by the total number of warnings issued during the warning outbreak event, events with higher STP values and more robust severe weather environments would have risen to the top, with the top WFO tornado warning outbreak being the infamous 27 April 2011 case from the Huntsville, Alabama, CWA. A similar rearrangement of the severe thunderstorm warning outbreaks would have a similar result. However, the averages would remain the same, as the warning outbreak instance was the desired ranking variable in this study owing to its implications for possible workload issues within a forecast office.

\section{Conclusion}

A dichotomy exists between tornado and severe thunderstorm warning outbreaks, as tornado warning outbreaks occur in extremely dangerous environments that are predominantly identified prior to convective initiation as moderate/high risk days (8 of 10 locally, 9 of 10 nationally) and PDS watches ( 6 of 10 locally, 8 of 10 nationally). In an analysis conducted by Rasmussen and Blanchard (1998) of 51 soundings that were in close proximity to EF2+ tornadoes, the upper quartile for 0-6-km bulk shear was 21-29 m s-1 (42-56 kt), while the upper quartile for mixed-layer CAPE was $1,877-3,028 \mathrm{~J} \mathrm{~kg}-1$. Using these ranges to indicate high instability and shear environments, 3 of 10 local events and 7 of 10 national events could be classified as having high CAPE and shear. High instability and shear environments are supportive of long-lived supercellular convection capable of producing tornadoes, large hail, and damaging winds (Thompson et al. 2012).

Many more warnings than average were issued during the top 10 tornado warning instances, both at the individual CWA and national levels, with the number of valid warnings (11-14 locally, 20-45 nationally) during the peak 1-min period of the outbreak in all cases falling above the 99th percentile. The warnings issued during these instances did not perform well as CSI scores fell an average of 0.058 locally and 0.074 nationally. The FAR increased 0.109 locally and 0.124 nationally, while the POD increased 0.324 locally and 0.282 nationally. While more tornadoes are being warned before they occur during these high-end events, more warnings are not being verified with an accompanying tornado event. As a result, the CSI score falls, indicating poorer performance of warnings during these warning outbreak events than average.

Meanwhile, severe thunderstorm warning outbreak instances occur in less severe environments and are often associated with slight/enhanced risks for severe weather issued by SPC (7 of 10). In lower shear environments, severe thunderstorms are unable to 
produce tornadoes, so hail and wind become the main threats to life and property, prompting the issuance of many severe thunderstorm warnings if severe storm coverage is great enough. This can especially occur during pulse thunderstorm events, such as the Knoxville, Tennessee, case from 2 July 2012 (Figs. 7b and 8b), as many smaller storms each require their own warning.

When numerous strong storms are forecast to occur, NWS WFOs likely account for this by having higher staffing levels to handle the anticipated demand of warning operations (Andra et al. 2002). However, if an office is staffed for a regular workday (i.e., low situational awareness or anticipation of numerous strong storms), there may not be enough warning meteorologists on duty to handle the amount of warnings that must be issued (WDTD 2016). As a result, the performance of those warnings may falter because there is not enough division of labor. Local severe thunderstorm warning outbreak events have a FAR and POD above the national average by 0.160 and 0.145 , respectively, while the CSI score is 0.107 below the national average. For the top 10 national events, the FAR increased by 0.187 , the POD increased by 0.054 , and the CSI dropped by 0.143 . Similar to the tornado warning outbreaks, severe thunderstorm warning outbreaks had lower CSI scores than average, as small increases in FAR outweigh any positive gains in POD in the calculation of the CSI score. Again, it is important to note the caveat that verification data are not perfect owing to (i) possible underreporting of severe weather during significant severe weather outbreaks and (ii) limited resources for conducting in-depth storm surveys. However, given the consistency between the four classes of warning outbreaks, this factor is unlikely to have influenced the verification results in a substantial manner.

Future efforts could explore the establishment of a robust definition of warning outbreaks, such that instances could be more readily identified in historical archives and in real-time. We hypothesize there to be a negative relationship between the number of simultaneous warnings in effect within a CWA and warning performance. If so, perhaps verification statistics, in addition to other indices, could aid in the establishment of such a definition. For example, Harrison and Karstens (2017) used convective days with warnings above one standard deviation of the mean warnings per day as a warning outbreak. An adaptation of this definition also may prove beneficial for further comprehensive studies of warning outbreaks.

While this study does not investigate the human factors that go into the warning process (Boustead and Mayes 2014), the results of this study are of importance to ongoing comprehensive efforts to improve the NWS warning system (Karstens et al. 2015), in addition to raising a general awareness of these extreme situations and their relationship to overall warning performance. When a severe convective event requires a large number of warnings, warning outbreaks can occur. Maintaining situational awareness is a critical element to providing effective warnings to the public. Seeking reductions in the FAR in these types of events should be done with caution, especially in tornado-supporting environments, as a large percentage of events (e.g., $43.5 \%$ of tornadoes in 2011) can be associated with warning outbreaks, and are therefore being warned for at a very high rate.

Acknowledgments. This paper was prepared with funding provided by the NOAA/Office of Education Hollings Scholarship Program and NOAA/Office of Oceanic and Atmospheric Research under NOAAUniversity of Oklahoma Cooperative Agreement \#NA11OAR4320072, United States Department of Commerce. The authors thank Kiel Ortega and two anonymous reviewers for their guidance and suggestions. The statements, findings, conclusions, and recommendations are those of the authors and do not necessarily reflect the views of NOAA or the United States Department of Commerce.

\section{REFERENCES}

Andra, D. L., Jr., E. M. Quoetone, and W. F. Bunting, 2002: Warning decision making: The relative roles of conceptual models, technology, strategy, and forecaster expertise on 3 May 1999. Wea. Forecasting, 17, 559566, Crossref.

Boustead, J. M., and B. E. Mayes, 2014: The role of the human in issuing severe weather warnings. Preprints, 27th Conf. on Severe Local Storms. Madison, WI, Amer. Meteor. Soc., 4B.2. [Available online at ams.confex. com/ams/27SLS/webprogram/Paper254547.html.]

Brooks, H. E., 2004: Tornado-warning performance in the past and future: A perspective from signal detection theory. Bull. Amer. Meteor. Soc., 85, 837-843, Crossref.

Christenberry, A., A. Lamers, B. Mejia, A. Dean, and S. Weiss, 2010: A multi-tiered verification of SPC tornado watches (2003-08). Preprints, 25th Conf. Severe Local Storms, Denver, CO, Amer. Meteor. Soc., P4.4 [Available online at ams.confex.com/ams/pdfpapers/176209.pdf.] 
Grams, J. S., R. L. Thompson, D. V. Snively, J. A. Prentice, G. M. Hodges, and L. J. Reames, 2012: A climatology and comparison of parameters for significant tornado events in the United States. Wea. Forecasting, 27, 106123 , Crossref.

Harrison, D. R., and C. D. Karstens, 2017: A climatology of operational storm-based warnings: A geospatial analysis. Wea. Forecasting, 32, 47-60, Crossref.

Karstens C. D., and Coauthors, 2015: Evaluation of a probabilistic forecasting methodology for severe convective weather in the 2014 Hazardous Weather Testbed. Wea. Forecasting, 30, 1551-1570, Crossref.

NWS, 2005: Working together to save lives: National Weather Service strategic plan for 2005-2010. NOAA/NWS, 33 pp. [Available online at www.nws.noaa.gov/sp/ NWS strategic plan 01-03-05.pdf.] , 2011a: Joplin, Missouri, Tornado - May 22, 2011. NOAA/NWS Central Region Service Assessment, 41 pp. [Available online at www.weather.gov/media/ publications/assessments/Joplin tornado.pdf.]

, 2011b: The historic tornadoes of April 2011. NOAA/ NWS Service Assessment, 76 pp. [Available online at www.weather.gov/media/publications/assessments/ historic tornadoes.pdf.] , 2015: Verification. NWS Instruction 10-1601, 8 pp. [Available online at www.nws.noaa.gov/directives/sym/ pd01016001curr.pdf.] , cited 2016: Service change notice 14-42: Corrected. [Available online at www.nws.noaa.gov/os/notification/ scn14-42day1-3outlooks_cca.htm.]

Rasmussen, E. N., and D. O. Blanchard, 1998: A baseline climatology of sounding-derived supercell and tornado forecast parameters. Wea. Forecasting, 13, 1148-1164, Crossref.

Rothfusz, L., C. Karstens, and D. Hilderbrand, 2014: Nextgeneration severe weather forecasting and communication. Eos, 95, 325-326, Crossref.

Smith, B., R. Thompson, J. Grams, C. Broyles, and H. Brooks, 2012: Convective modes for significant severe thunderstorms in the contiguous United States. Part I: Storm classification and climatology. Wea. Forecasting, 27, 1114-1135, Crossref.

Smith, R., 2014: The historic 2013 Oklahoma tornadoes: Highlights and success stories from WFO Norman. Preprints, Second Symp. on Building a Weather Ready Nation, Atlanta, GA, Amer. Meteor. Soc., 2.3. [Available online at ams.confex.com/ams/94Annual/webprogram/ Paper242041.html.]

Thompson, R. L., R. Edwards, and C. M. Mead, 2004: An update to the supercell composite and significant tornado parameters. Preprints, 22nd Conf. Severe Local Storms, Hyannis, MA, Amer. Meteor. Soc., P8.1. [Available online at ams.confex.com/ams/pdfpapers/82100.pdf.]
, B. T. Smith, J. S. Grams, A. R. Dean, and C. Broyles, 2012: Convective modes for significant severe thunderstorms in the contiguous United States. Part II: Supercell and QLCS tornado environments. Wea. Forecasting, 27, 1136-1154, Crossref.

WDTD, cited 2016: Optimizing office strategies for convective operations. [Available online at www.wdtb. noaa.gov/resources/PDS/Severe/PCU1/Modules/ Staffing/player.html.]

Wilks, D. S., 2006: Statistical Methods in the Atmospheric Sciences. 2nd ed. Academic Press, 648 pp. 